\title{
The Big Five, Type A Personality, and Psychological Well-Being
}

\author{
Richard E. Hicks ${ }^{1} \&$ Yukti P. Mehta ${ }^{1}$ \\ ${ }^{1}$ School of Psychology, Bond University, Robina, Queensland, Australia \\ Correspondence: Richard E. Hicks, School of Psychology, Faculty of Society and Design, Bond University, \\ Robina, Queensland-4229, Australia
}

Received: January 11, 2018

Accepted: February 8, 2018

Online Published: February 21, 2018

doi:10.5539/ijps.v10n1p49

URL: http://doi.org/10.5539/ijps.v10n1p49

\begin{abstract}
The aim of this research was to investigate how the Big Five and Type A personality variables relate to psychological well-being. Additionally, the study examined the effect of age on psychological well-being. Various social media sites such as Facebook were used to recruit 286 Participants (209 males, 74 females) from the community population. The sample was broad with an age range 18-85. Participants completed a demographic measure as well as the Ryff's Psychological Well-being scale, the International Personality Item Pool- Big Five Scale, the Framingham Type A Behavior Scale and a Social Desirability Scale. Pearson's product correlations and a hierarchical multiple regression were performed to determine the ability of the personality variables and Type A personality scores to predict psychological well-being. The results indicated that the personality variables (the Big Five) predicted psychological well-being but that the addition of variance from the Type A personality variable added insignificantly to the prediction. Psychological well-being was negatively correlated with age. Further studies on personality and psychological wellbeing are needed, including the role of mindfulness in contributing along with personality variables to psychological well-being.
\end{abstract}

Keywords: the big five, type a personality, psychological well-being, age

\section{Introduction}

\subsection{Overview}

Throughout the history of mental health, the focus on empirical work has been placed on healing the mentally ill though the study of the factors that contribute to healing and well-being has been largely unspecific (Xie, 2013) with most attention to negative symptoms and to causes rather than to elements that predict well-being, which has amplified the requirement to expand knowledge in this domain. In response to this need, it seems that positive psychological well-being (Keyes \& Provencher, 2011; Schmutte \& Ryff, 1997) could be a more effective goal than the current emphasis on symptom reduction. Marks and Shah (2004) argued that psychological well-being (PWB) is more than just happiness or satisfaction - PWB refers to being able to develop as a person and to being fulfilled and happy, and as contributing to community. As such wider measures of psychological well-being than those giving attention to symptom reduction are preferred. We discuss aspects of personality in relation to PWB in the next sections, including reference especially to age as well as gender and social desirability influences.

\subsection{Personality and $P W B$}

Personality variables (such as extraversion, conscientiousness and Type A personality) and personal strategies (such as mindfulness) contribute to this more positive approach that emphasises PWB (Brown, Ryan, \& Creswell, 2007; Schmutte \& Ryff, 1997). We give attention to personality variables in this paper. There have been several studies linking the Big Five variables with PWB (see section 1.3 next) and several studies examining Type A personality and ill-health (e.g., depression, anxiety and stress). However, no research seems to have examined both the Big Five and Type A together as predictors of PWB, despite the prevalence of Type A and Big Five research (e.g., in organisational and medical settings). We addressed this gap with the aim to clarify whether Type A personality contributed additional variance beyond the Big Five to psychological well-being. We also examined age and its relation to PWB. We did not examine the possibility that PWB would impact personality expression- that is, the inverse approach, as indicated in research by Scollon and Diener (2006) which showed that changes in satisfaction with work and relationships in adulthood contributed to changes in the traits of neuroticism and extraversion. We accepted the more common view that the relationships may be bi-directional 
but that personality variables more likely affect psychological wellbeing. We thus addressed how the Big Five variables and Type A personality scores impacted PWB in our study.

\subsection{The Big Five Personality Factors and PWB}

According to the APA guides (American Psychological Association, 2017), all individuals differ in patterns of thinking, feeling, and behaving. However, while emotions may fluctuate over the course of a day, personality is thought to remain stable after an individual reaches a certain age (McCrae \& Costa, 2003). One of the most researched personality models is the Big Five, measured by 'Big Five' inventories based on McCrae and Costa's (2003) earlier work; the Big Five consist of five components of personality: extraversion, agreeableness, conscientiousness, neuroticism, and openness to experience. John and Srivastava (1999) suggested that the core set of dispositional traits within the Big Five are the most prominent aspects of personality. The Big Five model provides an organized framework to which alternative measures can be added (Grant, Langan-Fox, \& Anglim, 2009).

Some previous research has focused on the relationship between the Big Five and PWB (e.g., Schmutte \& Ryff, 1997). More recently Siegler and Brummett (2000) analyzed the relationship between personality and PWB in a sample of 2,379 middle-aged adults, primarily focusing on the Big Five personality factors. The results indicated strong positive associations with extraversion, openness and (negatively) neuroticism but less intense associations with the other variables: conscientiousness and agreeableness. Research reported by Steel, Schmidt, and Shultz (2008) also showed neuroticism, agreeableness and extraversion were related to subjective wellbeing. In addition, research studies by Kokko, Tolvanen, and Pulkkinen (2013) examining middle adulthood relationships suggested that strongest associations were between neuroticism, extraversion and openness in relation to wellbeing in adulthood, but that conscientiousness and agreeableness were also significant correlates of well-being. Among other studies, Colling and Hicks (2007) also found close relationships between personality variables and general psychologi cal well-being with those at higher levels of well-being showing higher openness, extraversion and stress resilience (vs neuroticism) and lower conforming and competitive scores than those with lower levels of well-being.

Further investigation may be useful in determining the predictability of PWB from personality factors, especially given the broader positive make-up of PWB (see Method for more information on the PWB scale). There are other personality factors of importance in different contexts, such as Type A personality, perfectionism, honesty, and sensation seeking. Our current study examined whether Type A variance added to the Big Five variables in predicting psychological wellbeing because Type A personality (including its reverse in terms of low scores, Type B) has been of considerable interest in the medical, business, and professional worlds This has been noted mainly in the impacts of Type A personality on stress in the workplace and associated ill-health (e.g., Caplan \& Jones, 1975; Evan \& Palsane, 1987; Iwata, Suzuki, Saito, \& Abe, 1992; Janjhua, 2012; Milicic et al., 2016; Petticrew, Lee, \& McKee, 2012). Would a measure of Type A personality add to the Big Five measures in predicting well-being? The next section discusses what we know about Type A personality and well-being.

\subsection{Type $A$ and $P W B$}

In the last two decades, Type A and its opposite pole of Type B personality behavioral patterns have been the subject of interest by business, medical and psychology researchers alike (e.g., Caplan \& Jones, 1975; Petticrew, Lee, \& McKee, 2012). Studies suggest that people who possess the hard-driving, competitive, time-urgent Type A pattern of behaviors are twice as likely to develop coronary heart disease as are those with the more relaxed, easygoing Type B pattern (Kazmi, Amjad, \& Khan, 2008), that is, low levels of Type A behavior more like Type B behavior are linked with physical well-being. What is the evidence for a relationship to psychological well-being (PWB)? Some attention, though limited, has been given to examining how stress and Type A personality affect PWB (e.g., Jamal, 1990). Jamal (1990) examined the effects of job stress and Type A behavior on employee and organisational well-being with the study showing Type A personality employees (nurses in this study) experienced significantly more job stress and psychosomatic health problems as compared to Type B employees, similar to findings on white-collar workers outlined in a study by Evan and Palsane (1987). Janjhua (2012) found 160 healthcare professionals also responded differently to stress at work if they differed in personality Type A and Type B, with Type A individuals showing higher stress responses. The above studies indicate that Type A and Type B personality may be convincing predictors of PWB. However, whether the general community would respond in the same way did not seem to have been investigated in previous studies. Therefore, the current study examined the contribution of Type A personality to PWB in our sample and also investigated whether Type A personality added further information to the Big Five personality factors as contributors to psychological well-being. 


\subsection{Age and $P W B$}

It is also crucial to determine the relationship between age and PWB across the lifespan with the aim to develop interventions that help to improve the well-being of the population (Steptoe, Deaton, \& Stone, 2015). There have been contrasting studies regarding the association between age and PWB (cf., Springer, Pudrovska, \& Hauser, 2011). The most consistent is the "U-curve" in the relationship between age and PWB across individuals, countries, and cultures (Steptoe et al., 2015; Blanchflower \& Oswald, 2008): but this is not consistent. For example, Blanchflower and Oswald assessed PWB in a longitudinal cross-sectional data study on 500,000 randomly sampled participants from a Gallup survey and the U.S. General Social Surveys (GSS). The study suggested that PWB declines with age for about two decades, from early adulthood (20 to 40 years) up to the middle age years (40 to 60 years), and then turns upwards and increases. However, Baird, Lucas, and Donnellan (2010) in a separate study reported that well-being was mostly stable throughout adulthood with a downward slope in later life, suggesting a negative rather than positive trend towards the end of life. This could be due to decline in later life related to increasing health problems, the loss of social support, terminal illnesses, and social isolation in some cases- as indicated by Gerstorf, Ram, Estabrook, Schupp, Wagner, \& Lindenberger (2008). They used data from the German Socioeconomic Panel Study (GSOEP) and the British Household Panel Study to show that PWB declines rapidly in late life. Another recent study suggested the opposite- that the trend is up, not down (Galambos, Fanf, Krahn, Johnson, \& Lachman, 2015). Some specific studies aiming to clarify this situation include those that have highlighted frequency and intensity of emotion responses. Thus, a study by Carstensen, Mayr, Nesselroade, and Pasupathi (2009) found a positive rather than negative relationship between age and PWB when they analyzed five daily samples of momentary affect (e.g., "how are you feeling right now?"), over seven days, and showed that the frequency of negative emotions decreased at middle age but not the intensity. In addition, Garcia and Erlandsson (2011) showed variations in positive and negative affect reactions when frequencies and intensities of emotion responses were examined. Siegler and Brummett (2000) had also found similar results to those of Carstensen et al., in an earlier study. Several other studies have also examined personality impacts among older ages, including studies by Kokko, Tolvanen, and Pulkkinen (2013) and Wortman, Lucas, and Donnellan (2012). These conflicting and differing outcomes suggest that any conclusions regarding the relationship between age and PWB may be premature. Further investigation about level, changes in, and prediction of PWB across the lifespan could be helpful (Galambos et al., 2015).

\subsection{Age, Gender and Social Desirable Responding as Control Variables}

We examined this situation regarding age and PWB further, but used age as a control variable in the study because of the variations that had been found. We also used gender and social desirability responses as control variables as some previous studies had suggested variations existed also in the effects of gender and of 'favourable' responding (that may have distorted the true situation). It is well known that females appear to be susceptible more than are males to depression and anxiety (and therefore there could be some differences in regards to psychological well-being). On the other hand, a study of psychological well-being over the age ranges by Kokko et al. (2013) found no differences between males and females in their study of wellbeing in middle adulthood. Because of the mixed results we controlled for this variable in our study. However, because of known results concerning social desirability in self-report surveys such as ours we also controlled for this element. PWB is a significant factor in attitudes about living, and such information aids in improving quality of living. Therefore, the current study focused on how the Big Five factors contribute to PWB, and whether additional personality variables such as Type A personality might add significantly to our understanding of how personality contributes to psychological well-being, while we controlled for age, gender and social desirability responding.

\subsection{Aims of the Current Study}

The literature has established relationships between age and PWB, and between personality and PWB, particularly the Big Five variables and PWB. However, few studies seem to have examined the Big Five and Type A variables together and, given the emphasis on Type A (and its reverse, Type B) personality in much research, we examined these two thrusts (Big Five, and Type A). Thus, the aims of the current study were to examine:

(1) the empirical links between the Big Five personality variables and PWB in our general community sample, and

(2) the contribution of Type A personality to PWB, where in both cases PWB was measured by the Ryff Psychological Well-being scale. 
Based on the literature review and the definitions given above, it was hypothesized: (1) the Big Five personality variables would predict PWB; 2) Type A would predict PWB; and 3) Type A would explain additional variance in PWB beyond the Big Five personality variables (Extraversion, agreeableness, conscientiousness, neuroticism, openness to experience). We also examined the association between age and PWB.

\section{Method}

\subsection{Participants}

The initial sample included 290 participants, general community members, who were recruited using non-proportionate quota sampling via Qualtrics (see Qualtrics.com). The sample was then reduced to 286 participants after validity and data screening. Inclusion criteria required that participants (a) be between the age of 18 to 85 with internet access and (b) be able to comprehend the English language.

\subsection{Materials}

2.2.1 Demographics. In the initial section of the questionnaire, several demographic questions were asked. Participants specified their nationality, gender, and ethnicity with open responses. Closed questions were used to identify participants' age, occupation, status as students, and whether they practiced meditation and yoga. The information on yoga and meditation was obtained towards another study we were interested in, on mindfulness, personality and well-being (not part of the current paper). Demographic information for the current study is displayed in Table 1.

Table 1: Demographic Characteristic for the current study $(N=286)$

\begin{tabular}{ccc}
\hline & Frequency & Percentage (\%) \\
\hline Gender & 209 & 25.6 \\
Male & 74 & 72.3 \\
Female & & 10.7 \\
$18-24$ & 31 & 10 \\
$25-34$ & 29 & 15.6 \\
$35-44$ & 45 & 33.6 \\
$45-54$ & 97 & 21.6 \\
$55-64$ & 61 & 5.7 \\
$65-74$ & 16 & 1.4 \\
$75-84$ & 4 & 15 \\
Student & 44 & 84 \\
Yes & 242 & 10.7 \\
No & & 88.2 \\
Yoga & 31 & 20 \\
Yes & 255 & 78 \\
No & 60 & 26 \\
Yes & 226 & \\
No & & \\
\hline
\end{tabular}

2.2.2 International Personality Item Pool- Big Five Measurement (IPIP-Big Five; See Gow, Whiteman, Pattie, \& Deary, 2005). The IPIP measure used in the current study is a 20 -item short form that assesses five traits with 4 items each; extraversion (e.g. "Am the life of the party"), agreeableness (e.g., "Sympathize with others feelings"), conscientiousness (e.g., "Get chores done right away"), neuroticism (or 'emotional stability' as the other end of the continuum: e.g., "Have frequent mood swings"), and openness to experience (e.g., "Have a vivid imagination"). Participants indicate their answers on a six-point Likert scale ranging from 1 (Strongly agree) to 6 (Strongly disagree). Higher scores in each domain represent greater levels of extraversion, agreeableness, conscientiousness, neuroticism, and openness to experience. Studies have indicated sound psychometrics for the 20 -item short version of the Big Five. For example, Baldasaro, Shanahan, and Bauer (2013) reported Cronbach alpha coefficients ranging from 0.62 to .0 .71 for the Big Five variables in a sample of 26,666 youths. Another study (by Topolewska, Skimina, Wlodzimierz, \& Rowinski, 2014) on 903 people aged from 16 to 83 years revealed Cronbach's alpha coefficients from 0.61 to 0.82 . For the current study, the sub-scales displayed Cronbach's alpha coefficients between 0.59 and 0.65 , with 0.49 for the conscientiousness scale. Though in the moderate range these coefficients were deemed acceptable for research studies (Tabachnick \& Fidel, 2014), provided the results are treated with caution. 
2.2.3 Ryff's Psychological Well-being Scale: 54 item (Ryff, 1989; Ryff \& Keyes, 1995). This scale gives an overall PWB score as well as six sub-scale or area scores. The six elements are: autonomy, environmental mastery, personal growth, positive relations with others, purpose in life, and self-acceptance. The scale includes items such as "Most people see me as loving and affectionate.", responded to on a six-point Likert scale ranging from 1 (Strongly agree) to 6 (Strongly disagree). The scores on each dimension ranged from 54 to 270 with higher scores indicating a higher level of psychological well-being. For the purpose of this study, only the total score of PWB was used; therefore, the six sub-facets were not separately assessed in the current paper. Several studies have demonstrated good psychometrics for the total PWB scale- for example, Villar, Triado, and Celdran (2010) reported high internal consistency of the scale (Cronbach alpha $=0.71$ ), in line with Ryff and Keyes (1995) in their studies. In the current study a Cronbach's Alpha of 0.75 was found for the total scale.

2.2.4 The Framingham Type A Behaviour Scale (Friedman \& Rosenman, 1959): This is a 10- item self-report scale measuring Type A personality. Participants indicate their answer on a five-point Likert scale ranging from 1 (Strongly agree) to 5 (Strongly Disagree) on questions such as "Do you find it difficult to restrain yourself from hurrying others' speech?" Item responses yield a total score that can range from 10 to 50, where higher scores indicate higher Type A. Perlman, Hartman, and Lenahan (1984) reported high internal consistency of items within the scale, with a sample of 3000 men and women of ages 45 to 77 years (Cronbach's alpha $=.71, .70$ for men and women respectively). In the current study a Cronbach's alpha coefficient of .80 was found for the total scale.

2.2.5 The Marlowe-Crowne Social Desirability Scale Short Form C (SDS-C: See Reynolds, 1982; Zook \& Sipps, 1985). The Marlowe-Crowne SDS-C is a 13-item scale assessing the tendency to respond in a manner perceived favourably by others. Participants answer in a True or False format to items such as, "I have never intensely disliked someone." Reynolds (1982) assessed the psychometric properties of the short form in 608 undergraduate students aged 17 to 54 years finding, as per the Kuder-Richardson Formula 20, a KR-20 coefficient of 0.76 . The short form correlates highly with the standard Marlowe-Crowne 33-item scale $(\mathrm{r}=0.93)$. Zook and Sipps (1985) reported a six-week test re-test coefficient of 0.74 in a sample of 45 undergraduate students. In the current study a Cronbach's alpha coefficient of 0.69 was found.

\subsection{Procedure and Design}

Before data collection, ethical approval was obtained from the University's Human Research Ethics Committee. Participants were recruited via Qualtrics Online after a request for participation was distributed through various social media sites including Facebook. Initially participants were presented with a statement explaining that the research would assess their personality characteristics and psychological well-being; that the questionnaire would take approximately 30-45 minutes; that participation was voluntary, and that they could withdraw at any point without penalty. Furthermore, an explanatory note assured anonymity. Participants then proceeded through the online questionnaires. SPSS 20 was used for analyses. The study used a non-experimental survey design, which consisted of nine independent variables and one dependent variable. Relationships between variables were calculated using Pearson Product Moment calculations. Standard multiple regression and hierarchical multiple regression analyses were run to test the contribution of the Big Five and Type A personality variables, independent of the influences of age, gender and social desirability responding.

\section{Results}

\subsection{Data Diagnostics}

Before running analyses, visual analysis and frequency statistics were used to screen the data for errors or missing values. Several (7) participants were removed as data was missing; but otherwise assumptions of multicollinearity, singularity, linearity, homoscedasticity, and normality of residuals were all met, following Tabachnick and Fidel (2014).

\subsection{Preliminary Analyses- Correlation Coefficients}

Pearson Product moment correlation coefficients across the key personality and well-being variables are shown in Table 2 along with the Means and Standard Deviations of the variables. There was a positive relationship between extraversion, agreeableness, conscientiousness, and openness to experience and PWB, a negative relationship between Neuroticism and PWB, and limited associations of Type A with all personality variables and with PWB. Other correlations (not shown in Table 2) were calculated between each of age, gender, and social desirability, and the personality variables and wellbeing: age correlated significantly (negatively) with PWB and conscientiousness $(p<.01)$ and positively with openness and neuroticism $(p<.05)$; gender correlated positively with extraversion $(p<.01)$; and Social desirability correlated positively with conscientiousness $(p$ 
$<.01$ ). We decided it was appropriate to continue to control for the variables of age, gender and social desirability responding in the main analyses.

Table 2

Pearson's Correlation Summary Table, with Means and Standard Deviations for extraversion, agreeableness, conscientiousness, openness, type A and psychological well-being.

\begin{tabular}{lccccccccc}
\hline Scale & 1 & 2 & 3 & 4 & 5 & 6 & 7 & $M$ & $S D$ \\
\hline 1.Extraversion & - & & & & & & & 12.80 & 3.74 \\
2.Agreeable & .07 & - & & & & & & 9.35 & 3.40 \\
3.Con & -.04 & .09 & - & & & & 9.94 & 3.71 \\
4.Neuroticism & -.05 & -.07 & $-.19^{* *}$ & - & & & & 14.94 & 3.87 \\
5.Openness & $.26^{* *}$ & .06 & -.11 & .05 & - & & & 11.70 & 3.79 \\
6.Type A & $.17^{* *}$ & -.06 & -.06 & .11 & $.11^{*}$ & - & & 24.10 & 8.14 \\
7.PWB & $.30^{* *}$ & $.22^{* *}$ & $.33^{* *}$ & $-.38^{* *}$ & $.15^{*}$ & -.02 & - & 127.70 & 43.89 \\
\hline
\end{tabular}

Note. ${ }^{*} p<.05,{ }^{* *} p<.01,{ }^{* * *} p<.001 . \mathrm{PWB}=$ Psychological Well-being,

Con $=$ Conscientiousness,

\subsection{Main Analyses: Hierarchical Multiple Regression}

A hierarchical multiple regression analysis (with $n=286$ ) was conducted (see Table 3), with age, gender and social desirability (SDS) entered at Step 1 to act as control variables. The total scores of Type A personality and sub scale scores of the Big Five personality variables (neuroticism, extraversion, openness to experience, agreeableness, and conscientiousness) were entered at step 2. At step two, Type A and the five personality variables were added to the model, yielding $F(9,272)=17.92, p<.001$. The addition of Type A and the five personality variables combined, contributed significantly to the model and added $32 \%$ unique variance in predicting PWB, $\Delta F(6,272)=23.24, p<.001$. Inspection of the beta weights showed that Type A, contrary to earlier expectations, did not account on its own for significant variance in PWB. In line with the hypothesis, however, there was a significant relationship between all five traits of personality and PWB, with neuroticism (negatively), conscientiousness and extraversion showing the highest loadings. Age continued to contribute to prediction of (negative) psychological wellbeing.

Table 3

Hierarchical Multiple Regression Analysis predicting Psychological Well-being from, Gender, Social desirability (SDS), the big five Personality Variables (Extraversion, agreeableness, conscientiousness, neuroticism and openness to experiences), and Type A

\begin{tabular}{llccccc}
\hline Predictor & & $\mathrm{B}$ & $\mathrm{SEB}$ & $\beta$ & $\mathrm{R}^{2}$ & $\Delta \mathrm{R}^{2}$ \\
& & & & & .04 & .04 \\
Step 1 & Constant & 111.66 & 29.65 & & .04 & \\
& Gender & $11.25^{*}$ & 5.85 & .13 & & \\
& Age & $-5.67^{* * *}$ & 1.83 & -.18 & & $.32 * * *$ \\
& SDS & .94 & 1.24 & .04 & & \\
Step 2 & & & & & \\
& Constant & 89.41 & 28.42 & & .36 & \\
& Gender & 9.42 & 4.83 & .09 & & \\
& Age & $-4.32^{* *}$ & 1.51 & -.14 & & \\
SDS & -.55 & 1.04 & -.02 & & \\
& Type A & -.07 & .26 & -.01 & & \\
& Ext & $3.09^{* * *}$ & .61 & .26 & & \\
& Agr & $1.77^{*}$ & .63 & .13 & & \\
& Con & $3.21^{* *}$ & .60 & .27 & & \\
& Neu & $-3.42^{* * *}$ & .56 & -.30 & & \\
& Open & $1.68^{*}$ & .58 & .14 & & \\
& & & & & \\
& & & & &
\end{tabular}

Note: $* \mathrm{p}<.05,{ }^{* *} \mathrm{p}<.01,{ }^{* * *} \mathrm{p}<.001$ 


\section{Discussion}

\subsection{Results and Comments}

The main aim of the current study was to investigate the contribution of personality variables to Psychological Well-Being (PWB). The results concerning age are discussed first, as one of the control variables used in subsequent analyses. Past research had found mixed results in the prediction of PWB across age (Baird et al., 2010; Carstensen et al., 2009; Siegler \& Brummett, 2000; Steptoe et al., 2015). We have added further to this literature. We found a significant negative correlation between age and PWB. This finding is in line with the research from Baird et al. (2010) and Gerstorf et al. (2008) who found that PWB was more likely to decline in later life. However, the findings are inconsistent with study reports of Carstensen et al. (2009) and Siegler and Brummett (2000), and of Galambos et al. (2015), who each found that PWB improved with age. Ours was a cross-sectional study but adds to the debate, suggesting however, that more research is needed and that individual differences may impact more than is recognised currently. Certainly attention to issues such as intensity and frequency of experienced emotions and age is needed, along with attention to life experiences in later life, such as degree of physical health, social support and social isolation (c.f., Gerstorf et al., 2008). We decided to control for age given the results we had found that age was related in our sample to psychological wellbeing.

The first hypothesis, that the Big Five Personality factors would make significant contributions to PWB, was fully supported. All five personality variables were significantly associated with PWB. The results were consistent with some previous studies (e.g., Kokko et al., 2013) but not with others where mixed relationships were found (e.g., Mobarakeh et al., 2015 - who found that conscientiousness was not related to PWB). The current study's results suggest that neuroticism (negatively), extraversion, and conscientiousness are significantly and strongly associated with PWB, while agreeableness and openness are significantly but less strongly related. Consistent across numerous studies has been the finding that neuroticism and extraversion are both strong predictors of psychological and/or subjective wellbeing (e.g., the current study and those of Colling \& Hicks, 2008; Kokko et al., 2013; Siegler \& Brummett, 2000; Steel et al., 2008). The current study listed conscientious as a strongly related predictor of PWB, partially in line with most other studies that make it a significant but not strongly significant factor (e.g., Kokko et al., 2013); further the current study suggested openness and agreeableness were moderately significant- selected other studies have placed it at different levelsincluding in the strongly significant ranges (cf., Colling \& Hicks, 2007; Kokko et al., 2013; Siegler \& Brummett, 2000). Agreeableness came through in most studies at moderate levels of significance in predicting psychological wellbeing or similar positive mental health measure.

The second hypothesis that Type A personality would be correlated with and predict PWB was not supported. No previous studies to our knowledge had looked at the relationship between Type A and PWB, though subjective well-being had been linked in some studies. However, Type A had been found to be related to anxiety and to depression (Caplan \& Jones, 1975) and it was expected that Type A would correlate significantly and negatively with PWB, given that depression and anxiety had also been found to be negatively correlated with PWB (Evan \& Palsane, 1987; Kazmi et al., 2008). This did not occur. It could be that Type A personality is indeed not associated with PWB as assessed in our study using Ryff's Psychological Well-being scale; or that Type A personality is related, but that our Type A assessment measure was inadequate. Further studies using other measures of Type A and-or of psychological well-being might clarify this issue. It could be that selected facets of psychological wellbeing are more important than others and more detailed analyses of the six facets in Ryff's scale is proposed.

The final hypothesis that Type A personality would add to the Big Five personality variables in predicting PWB was not supported. The correlation between Type A personality and PWB was not significant and hence Type A scores could not add further significant variance in prediction of PWB beyond what was already incorporated in the Big Five personality variables. This result, that Type A variance did not relate to or add to the Big Five personality variables in predicting psychological wellbeing was unexpected, given that several studies had indicated potential links. For example, Caplan and Jones (1975) had linked Type A to depression and anxiety and several more recent studies had suggested similar links to stress in clinical and organisational contexts (e.g., Janjhua, 2012; Milicic et al., 2016; Petticrew et al., 2012). The evidence has indicated that Type A personality has links with negative aspects of wellbeing; our study suggests that there are no similar links with positive aspects of wellbeing, as measured by the total score on the Psychological Wellbeing scale. It may be that other measures of wellbeing (such as life satisfaction and subjective wellbeing measures - cf., Baird et al., 2010; Steel et al., 2008) would yield different results. It may also be that specific scales within Ryff's PWB scale may relate directly to Type A scores; we did not examine these specific scales in the current study. 


\subsection{Limitations and Strengths}

A limitation of the study was the somewhat limited sample size (though 286 is sufficient to pick up most significant relationships), and the participant sample showed an imbalance in gender with rather more males than females responding, and an imbalance in age ranges (though the spread of numbers across the age groupings from 18-24, through to 75-84 as shown in Table 1 was good but could have benefited from more respondents in the two lower age bands to age 34). We used self-report surveys on both personality and PWB responses and though we controlled for social desirable responding there are still inherent weaknesses in such survey research (such that self-perceptions of health and wellbeing may not be accurate reflections of reality). This is a common weakness in all or nearly all survey research and must be taken into account in considering the research findings. Further, we used the internet for the sample respondents and drew responses mainly from Australia but also from around the world. There may have been limited impacts from such snow-ball sampling to friends on Facebook and other internet sources but this is not known and was not controlled for in the study. Another overall limitation in the present study was the conceptualisation from the beginning that personality variables would predict PWB rather than that PWB may in fact affect personality expression (Scollon \& Diener, 2006). Finally, for this study we used the total score on the Ryff PWB scale to measure psychological wellbeing - and similarly we chose particular measures of the Big Five and of Type A, rather than alternative forms and/or lengthier versions that might have been more accurate measures. Nevertheless, despite the weaknesses in the study, a number of results have been demonstrated with support for previous research and with new information, especially in relation to the (non-) contribution of Type A personality as a predictor of either positive or negative wellbeing as assessed using the PWB scale. However, in future studies, it could be interesting to see how the sub-components of Ryff's (1989) measure are related to the personality variables including Type A personality.

\subsection{Conclusion}

The current study has successfully shown and confirmed the importance of personality factors (extraversion, conscientiousness, openness to experience, agreeableness, \& neuroticism) and of age in prediction of PWB. Type A personality did not however relate to PWB or add any significant variance over and above the Big Five personality factors in predicting PWB. Future studies could focus on more specific aspects involved in psychological wellbeing, and/or on developing long-term interventions that assist in reducing the negative effects of high early life scores on Neuroticism (vs Emotional Stability) in their impacts on current and later life psychological and physical wellbeing. Tailoring health and wellness programs to improve quality of life in all age groups with special attention given to individual personality characteristics (especially the Big Five) could increase lifestyle health behaviors that promote psychological wellbeing.

\section{References}

American Psychological Association http://www.apa.org/topics/personality/

(2017). Personality. Retrieved from:

Baird B. M., Lucas, R. E., \& Donnellan M. B. (2010). Life Satisfaction Across the Lifespan: Findings from Two Nationally Representative Panel Studies. Social Indicators Research, 99(2). 183-203. https://doi.org/10.1007/s11205-010-9584-9

Baldasaro, E. R., Shanahan, J. M., \& Bauer, D. (2013). Psychometric of the Mini-IPIP in a Large, Nationally Representative Sample of Young Adults. Journal of Personality Assessment, 95(1), 74-84. https://doi.org/10.1080/00223891.2012.700466

Blanchflower, G. D., \& Oswald, J. A. (2008). Is well-being U-shaped over the life cycle? Social Science \& Medicine, 66(8), 1733-1749. https://doi.org/10.1016 2008.01.030

Brown, K., Ryan, R., \& Creswell, J. (2007). Mindfulness: Theoretical Foundations and Evidence for its Salutary Effects. Psychological Inquiry, 18(4), 211 - 237. https://doi.org/10.1080/10478400701598298

Caplan, D. R., \& Jones, W. K. (1975). Effects of Work Load, Role Ambiguity, and Type A personality on anxiety, depression, and heart rate. Journal of Applied Psychology, 60(6), 713-719. https://doi.org/10.1037/0021-9010.60.6.713

Carstensen, L. L., Mayr, U., Nesselroade, R. J., \& Pasupathi, M. (2009). Emotional Experience in Everyday Life Across the Adult Life Span. Journal of Personality and Social Psychology, 79(4), 644-655. https://doi.org/1037O022-3 514.79.4.644 
Colling, G. V. S., \& Hicks, R. E. (2007). Can work preferences (personality based) differentiate between employees scoring high or low in general mental health? In K. Moore (Ed.), Proceedings of the $42^{\text {nd }} A P S$ Annual Conference (Australian Psychological Society), Psychology making an impact (pp.93-97). Queensland, Australia: Australian Psychological Society.

Evan, G. W., \& Palsane, M. N. (1987). Type A behaviour and occupational stress: A cross-sectional study of blue collar workers. Journal of Personality and Social Psychology, 52, 1002-1007. https://doi.org/10.1037/0022-3514.52.5.1002

Galambos, N. L., Fang, S., Krahn, H. J., Johnson, M. D., \& Lachman, M. E. (2015). Up, not down: The age curve in happiness from early adulthood to midlife in two longitudinal studies. Developmental Psychology, 51(11), 1664-71. https://doi.org/10.1037/dev0000052

Garcia, D., \& Erlandsson, A. (2011). The relationship between personality and subjective well-being: Different association patterns when measuring the affective component in frequency and intensity. Journal of Happiness Studies, 12(6), 1023-1034. https://doi.org/10.1007/s10902-010-9242-6

Gerstorf, D., Ram, N., Estabrook, R., Schupp, J., Wagner, G. G., \& Lindenberger, U. (2008). Life satisfaction shows terminal decline in old age: Longitudinal evidence from the German Socio-Economic Panel Study (SOEP). Developmental Psychology, 44, 1148-1159. https://doi.org/10.1037/0012-1649.44.4.1148

Gow, A. J., Whiteman, M. C., Pattie, A., \& Deary, I. J. (2005). Goldberg's 'IPIP' Big-Five factor markers: Internal consistency and concurrent validation in Scotland. Personality \& Individual Differences, 39(2), 317-329. https://doi.org/10.1016/j.paid.2005.01.011

Grant, S., Langan-Fox, J., \& Anglim, J. (2009). The big five traits as predictors of subjective and psychological well-being. Psychological reports, 105(1), 205-231. https://doi.org/10.2466/PR0.105.1.205-231

Iwata, N., Suzuki, K., Saito, K., \& Abe, K. (1992), Type A personality, work stress and psychological distress in Japanese adult employees. Stress Medicine, $8,11-21$. https://doi.org/10.1002/smi.2460080103

Jamal, M. (1990). Relationship of job stress and Type-A behavior to employees' job satisfaction, organisational commitment, psychosomatic health problems, and turnover motivation. Human Relations, 43, 727-738. https://doi.org/10.1177/001872679004300802

Janjhua, Yasmin C. (2012). Behavior of personality type toward stress and job performance: A study of healthcare professionals. Journal Family Medicine \& Primary Care, 1(2), 109. https://doi.org/10.4103/2249-4863.104969

John, O. P., \& Srivastava, S. (1999). The Big-Five trait taxonomy: History, measurement, and theoretical perspectives. In L. A. Pervin \& O. P. John (Eds.), Handbook of personality: Theory and research, 2, 102-138. New York: Guilford Press.

Kazmi, R., Amjad, S., \& Khan, D. (2009). Individual differences and stress-performance relationship. Journal of Ayub Medical College Abbottabad, 21(3), 172-175

Keyes, L. M. C., \& Provencher, L. H. (2011). Complete mental health recovery: bridging mental illness with positive mental health. Journal of Public Mental Health, 10(1), 57-69. https://doi.org/10.1108/17465721111134556

Kokko, K., Tolvanen, A., \&Pulkkinen, L. (2013). Associations between personality traits and psychological well-being across time in middle adulthood. Journal of Research in Personality, 748-756. https://doi.org/10.1016/j.jrp.2013.07.002

Marks N., \& Shah, H. (2004). A well - being manifesto for a flourishing society. Journal of Public Mental Health, 3(4), 9-15. https://doi.org/10.1108/17465729200400023

McCrae, R. R., \& Costa, P. T. (2003). Personality in adulthood: A five-factor theory perspective. Guilford Press. https://doi.org/10.4324/9780203428412

Milicic, D., Brajkovic, L., Macek, J.L., Andic, A., Ardilic, Z., Buratovic, T., \& Marcinko, D. (2016). Type A personality, stress, anxiety and health locus of control in patients with acute myocardial infarction. Psychiatrica Danubina, 28(4), 409-414.

Petticrew, M. P., Lee, K., \& McKee, M. (2012). Type A Behavior Pattern and Coronary Heart Disease: Philip Morris's "Crown Jewel." American Journal of Public Health,102(11), 2018-2025. https://doi.org/10.2105/2012.300816 
Perlman, B., Hartman, A. E., \& Lenahan.B. (1984). Validation of a Six Item Questionnaire For Assessing Type A Behaviour. U.S. Department of Education, 143-160

Reynolds, W. M. (1982). Development of reliable and valid short forms of the Marlowe - Crowne Social $\begin{array}{llll}\text { Desirability } \quad \text { Scale. Journal of } & \text { Clinical } & \text { Psychology, 38(1), } & \text { 119-125. }\end{array}$ https://doi.org/10.1002/1097-4679(198201)38:1<119::AID-JCLP2270380118>3.0.CO;2-I

Ryff, D., C. (1989). Happiness is everything, or is it? Exploration on the meaning of Psychological Well-being. Journal of Personality and Social Psychology, 57(6), 1069-1081. https://doi.org/10.1037/0022-3514.57.6.1069

Ryff, C., \& Keyes, C. (1995). The structure of psychological well-being revisited. Journal of Personality and Social Psychology, 69, 719-727. https://doi.org/10.1037/0022-3514.69.4.719

Seifert, A. T. (2005). The Ryff Scales of Psychological Well-being. Centre of Inquiry. Retrieved from http://www.liberalarts.wabash.edu/ryff-scales/

Schmutte, P. S., \& Ryff, C. D. (1997). Personality and Well-Being: Reexamining Methods and Meanings. Journal of Personality and Social Psychology, 73(3), 549-559. https://doi.org/10.1037/0022-3514.73.3.549

Scollon, C. N., \& Diener, E. (2006). Love, work, and changes in extraversion and neuroticism over time. Journal of Personality and Social Psychology, 91, 1152-1165. https://doi.org/10.1037/0022.3514.91.6.1152

Siegler, I. C., \& Brummett, B. H. (2000). Associations among NEO personality assessments and well-being at $\begin{array}{lllll}\text { midlife: } & \text { Facet-level aning, 15(4), } & 710 .\end{array}$ https://doi.org/10.1037//0882-7974.15.4.7IO

Springer, K. W., Pudrovska, T., \& Hauser, R. M. (2011). Does psychological well-being change with age? Longitudinal tests of age variations and further exploration of the multidimensionality of Ryff's model of $\begin{array}{llll}\text { psychological well-being. Social } & \text { Science } & \text { Research, 40(1), }\end{array}$ https://doi.org/10.1016/j.ssresearch.2010.05.008

Steel, P., Schmidt, J., \& Shultz, J. (2008). Refining the relationship between personality and subjective well-being. Psychological Bulletin, 134(1), 138-161. https://doi.org/10.1037/0033-2909.134.1.138

Steptoe, A., Deaton, A., \& Stone, A. A. (2015). Subjective Wellbeing, Health, and Ageing. The Lancet, 385, 640-648. https://doi.org/10.1016/S0140-6736(13)61489-0

Tabachnick, M. L., \& Fidel, L. S. (2014). Using Multivariate Statistics (6th ed.). Boston: Pearson.

Topolewska, E., Skimina, E., Strus, W., Cieciuch, J., \& Rowinski, T. (2014). The short IPIP-BFM-20 questionnaire for measuring the Big Five. Annals of Psychology, 17(2), 385-402.

Villar, F., Triado, C., \& Celdran, M. (2010). Measuring Well-Being among Spanish older adults: Development of a Simplified Version of Ryff's Scales of Psychological Well-Being Psychological Reports, 107(1), 265-280. https://doi.org/10.2466/02.07.08.10.21.PR0.107.4

Wortman, J., Lucas, R.E., \& Donnellan, M.B. (2012). Stability and change in the Big Five personality domains: Evidence from a longitudinal study of Australians. Psychology and Aging, 27, 867-874. https://doi.org/10.1037/a0029322

Xie, H. (2013). Strengths-Based Approach for Mental Health Recovery. Iranian Journal of Psychiatry and Behavioral Sciences, 7(2), 5-10.

Zook, I. I. A., \& Sipps, G.J. (1985). Cross-validation of a short form of the Marlowe-Crowne Social Desirability $\begin{array}{llll}\text { Scale. Journal of } & \text { Clinical } & \text { 236-238. }\end{array}$ https://doi.org/10.1002/1097-4679(198503)41:2<236::AID-JCLP2270410217>3.0.CO;2-H

\section{Copyrights}

Copyright for this article is retained by the author(s), with first publication rights granted to the journal.

This is an open-access article distributed under the terms and conditions of the Creative Commons Attribution license (http://creativecommons.org/licenses/by/4.0/). 